\title{
Deviation of dental implants placed using a novel 3D-printed surgical guide: An in vitro study
}

\author{
Enas Abdalla Etajuri ${ }^{1, A-D, F}$, Eshamsul Suliman ${ }^{1, A, F}$, Wan Adida Azina Mahmood ${ }^{1, A, E}$, Norliza lbrahim 2,B,E, Muaiyed Buzayann, \\ Noorhayati Raja Mohd ${ }^{1, B, E}$ \\ ${ }^{1}$ Department of Restorative Dentistry, Faculty of Dentistry, University of Malaya, Kuala Lumpur, Malaysia \\ ${ }^{2}$ Department of Oral and Maxillofacial Surgical Sciences, Faculty of Dentistry, University of Malaya, Kuala Lumpur, Malaysia \\ A - research concept and design; $\mathrm{B}$ - collection and/or assembly of data; $\mathrm{C}$ - data analysis and interpretation; \\ $D$ - writing the article; $E$ - critical revision of the article; $F$ - final approval of the article
}

\author{
Address for correspondence \\ Enas Abdalla Etajuri \\ E-mail: enas@um.edu.my \\ Funding sources \\ Research grant No. PPPC/C1-2015/DGS/25, \\ University of Malaya, Kuala Lumpur, Malaysia. \\ Conflict of interest \\ None declared
}

Received on May 2, 2020

Reviewed on May 30, 2020

Accepted on June 15, 2020

Published online on December 31, 2020

Cite as

Etajuri EA, Suliman E, Mahmood WAA, lbrahim N, Buzayan M,

Mohd NR. Deviation of dental implants placed using a novel

3D-printed surgical guide: An in vitro study. Dent Med Probl.

2020;57(4):359-362. doi:10.17219/dmp/123976

DOI

$10.17219 / \mathrm{dmp} / 123976$

Copyright

○) 2020 by Wroclaw Medical University

This is an article distributed under the terms of the

Creative Commons Attribution 3.0 Unported License (CC BY 3.0)

(https://creativecommons.org/licenses/by/3.0/).

\begin{abstract}
Background. There is very little literature available on the reliability of the rapid prototyping technology in the production of three-dimension (3D)-printed surgical guides for accurate implant placement.

Objectives. The aim of the study was to evaluate the deviation of implant placement performed with a surgical guide fabricated by means of the rapid prototyping technique (the PolyJet ${ }^{\text {TM }}$ technology).

Material and methods. Twenty sheep mandibles were used in the study. Pre-surgical cone-beam computed tomography (CBCT) scans were acquired for the mandibles by using the Kodak $90003 \mathrm{D}$ cone-beam system. Two implants with dimensions of $4 \mathrm{~mm}$ in diameter and $10 \mathrm{~mm}$ in length were virtually planned on the $3 \mathrm{D}$ models of each mandible by using the Mimics software, v. 16.0. Twenty surgical guides were designed and printed using the PolyJet technology. A total of 40 implants were placed using the surgical guides, 1 on each side of the mandible (2 implants per mandible). The post-surgical (BCT scans of the mandibles were performed and superimposed on the pre-surgical CBCT scans. The amount of deviation between the virtually planned placement and the actual implant placement was measured, and a descriptive analysis was done.

Results. The results showed that the mean deviation at the implant coronal position was $1.82 \pm 0.74 \mathrm{~mm}$, the mean deviation at the implant apex was $1.54 \pm 0.88 \mathrm{~mm}$, the mean depth deviation was $0.44 \pm 0.32 \mathrm{~mm}$, and the mean angular deviation was $3.01 \pm 1.98^{\circ}$.

Conclusions. The deviation of dental implant placement performed with a 3D-printed surgical guide (the PolyJet technology) is within the acceptable 2-millimeter limit reported in the literature.
\end{abstract}

Key words: dental implant, 3D-printing, cone-beam computed tomography, computer-aided design/ computer-aided manufacturing 


\section{Introduction}

Osseointegration is well-known and established as the key factor for success in implant dentistry, ${ }^{1-3}$ but nowadays, the success of dental implants should also be determined by functional and esthetic restorative objectives. ${ }^{4,5}$ The use of three-dimensionally (3D) guided implant placement is currently recommended to achieve these objectives and avoid surgical complications, such as unfavorable anatomical structures. ${ }^{6,7}$

In the $21^{\text {st }}$ century, digitalization plays a role in all aspects of life. It also refers to the field of dentistry. In implantology particularly, precise implant placement has become more predictable with the development of technology and with the invention of cone-beam computed tomography $(\mathrm{CBCT})$ imaging in conjunction with the 3D reconstruction of structures, the virtual planning of the implant and surgical guides constructed using stereolithography (SLA). ${ }^{8,9}$

Compared with the conventional computed tomography (CT), CBCT generates 6 times less radiation, enabling the acquisition of the 3D images of the soft and hard tissues of the patient with lower doses of radiation. ${ }^{10-12}$ A CBCT scan is able to show objects in $3 \mathrm{D}$ as precisely as a CT scan and can help replicate the tissues accurately enough to plan surgical procedures. ${ }^{13,14}$

There are several software programs that permit virtual implant planning by using the 3D images of CBCT scans. A virtually planned implant can later be transferred to the patient; however, the accurate transfer of a virtually planned implant to the patient is the main concern. ${ }^{8,15-17}$

The positioning of a virtually planned implant in the patient's mouth can be performed using a surgical guide, which can be either constructed on a cast (the conventional manual method) or created virtually by means of computer software and a milling process with the SLA technology. ${ }^{18}$ The PolyJet ${ }^{\mathrm{TM}}$ technology is an additive manufacturing process in which inkjet technologies are used to create physical models. The head of the inkjet moves along the $\mathrm{X}$ and $\mathrm{Y}$ axes, depositing the layers of the photopolymer, which are exposed to ultraviolet lamps for curing. The layer thickness produced in this process is $16 \mu \mathrm{m}$, which is considered high-resolution production. ${ }^{19}$

The aim of the present study was to evaluate deviations in implant placement performed using a surgical guide produced by the rapid prototype technique (the PolyJet technology).

\section{Material and methods}

A total of 20 sheep mandibles were collected from typical butcher shops and scanned using the Kodak 9000 3D cone-beam system (Carestream Health Inc., Rochester, USA). The setting of the CBCT machine was standardized at $70 \mathrm{kV}, 120 \mathrm{mAs}$. The data was saved as DICOM files and sent to the Mimics software, v. 16 (Materialise NV, Leuven, Belgium). For each of the 20 scanned mandibles, 2 implants (Neobiotech Co., Ltd., Seoul, South Korea) $-4 \mathrm{~mm}$ in diameter and $10 \mathrm{~mm}$ in length - were virtually planned on the Mimics software 3D model of the mandible.

A total of 40 virtual implants were planned (Fig. 1). The data was transformed into STL files and sent to the Centre for Biomedical and Technology Integration (CBMTI) Sdn. Bhd, at the Institute of Postgraduate Studies (IPS) of the University of Malaya in Kuala Lumpur, Malaysia, to design and print surgical guides for each mandible by using the PolyJet technology (Solid Concepts Inc., Valencia, USA).

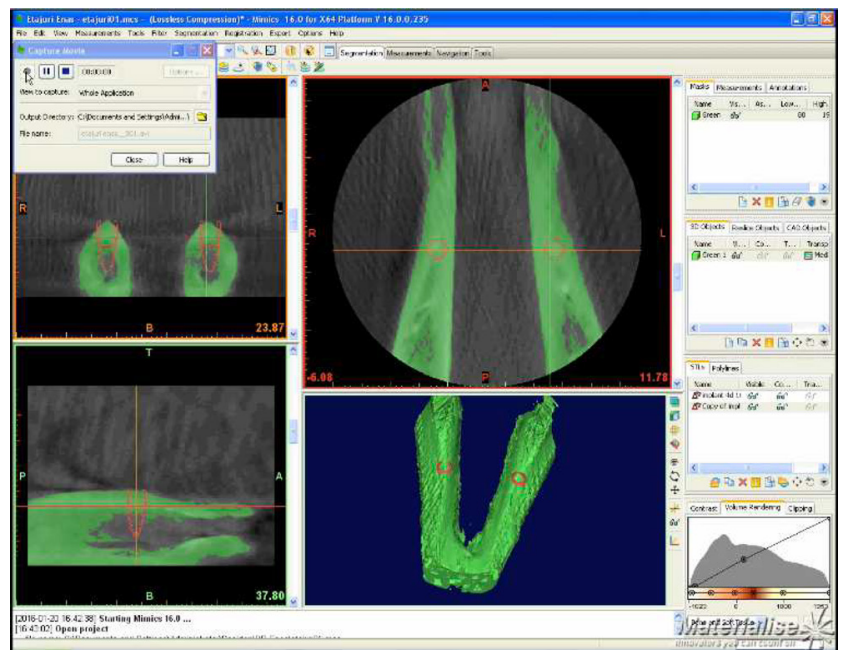

Fig. 1. Screenshot of virtual implant planning with the Mimics software

A total of 20 surgical guides were designed to accept a series of 5 stainless steel drill guides (sleeves) to accommodate 1.9-, 2.2-, 2.9-, 3.4-, and 4-millimeter twist drills. Each mandible sample was fixed on a plastic plate by using the ProBase ${ }^{\circledR}$ cold-cure acrylic resin (Ivoclar Vivadent Inc., Schaan, Liechtenstein) for drilling and scanning. Two implants were placed on the right and left sides of each mandible (Fig. 2).

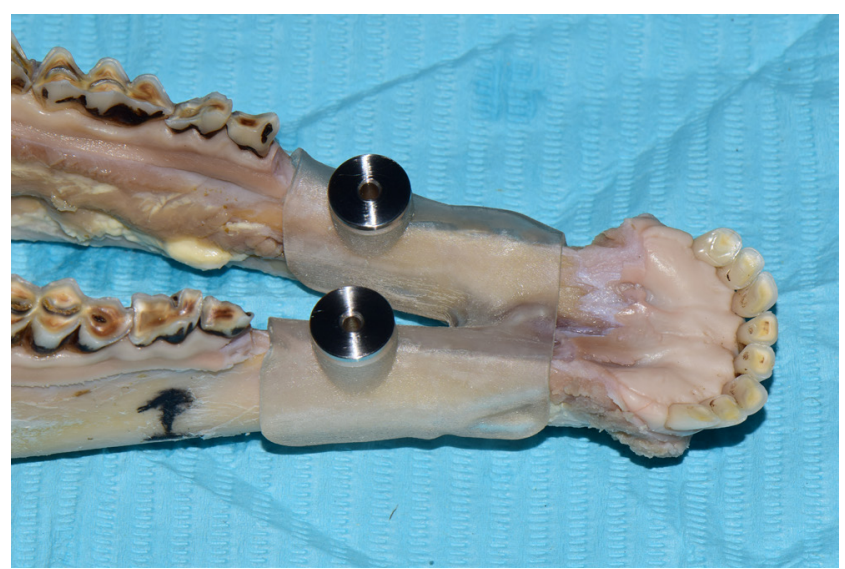

Fig. 2. 3D-printed surgical guide and the drilling guides fitted on a mandible 
Post-surgical CBCT scans were taken, adhering to the same position and settings of the machine as those used to perform pre-surgical CBCT scans. The data was sent to the Mimics software. The pre- and post-surgical 3D models were superimposed (Fig. 3), and the implant deviations in the coronal, apex, depth, and angular positions were measured using the Mimics software. The data was collected and a descriptive statistical analysis was done using IBM SPSS Statistics for Windows, v. 24.0 (IBM Corp., Armonk, USA).

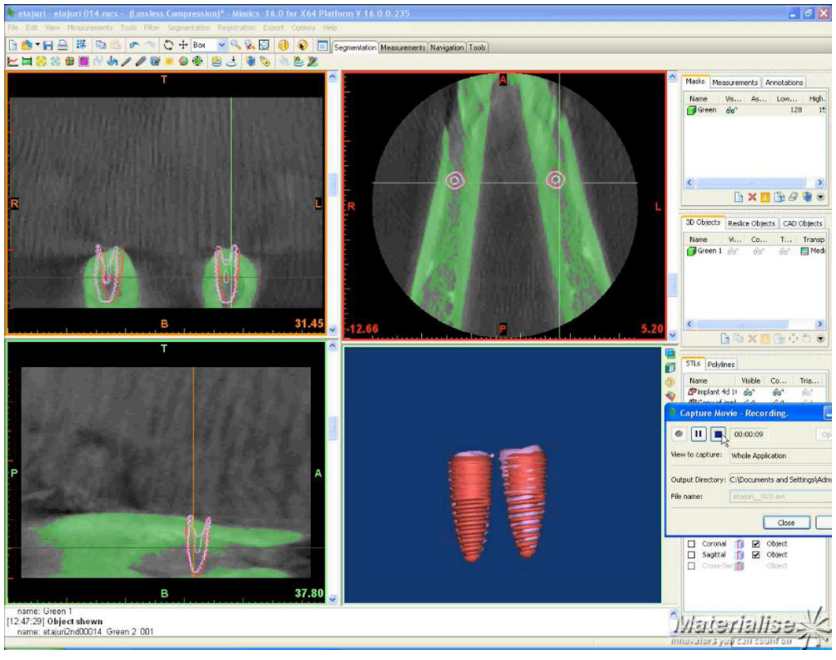

Fig. 3. Screenshot of the Mimics software showing the positions of the virtual and the placed implants after superimposing

\section{Results}

The implant deviation recorded at the coronal position ranged from $0.68 \mathrm{~mm}$ to $3.85 \mathrm{~mm}$. The apex deviation ranged from $0.09 \mathrm{~mm}$ to $3.91 \mathrm{~mm}$. The depth deviation ranged from $0.02 \mathrm{~mm}$ to $1.19 \mathrm{~mm}$. The recorded angular deviation ranged from $0.38^{\circ}$ to $6.72^{\circ}$ (Table 1 ).

Table 1. Deviations of implant placement performed using a 3D-printed surgical guide

\begin{tabular}{|l|c|c|c|c|}
\multicolumn{1}{|c|}{ Deviation } & Minimum & Maximum & $M$ & SD \\
\hline Coronal $[\mathrm{mm}]$ & 0.68 & 3.85 & 1.82 & 0.74 \\
Apex $[\mathrm{mm}]$ & 0.09 & 3.91 & 1.54 & 0.88 \\
Depth $[\mathrm{mm}]$ & 0.02 & 1.19 & 0.44 & 0.32 \\
Angular $\left[^{\circ}\right]$ & 0.38 & 6.72 & 3.01 & 1.98 \\
\hline
\end{tabular}

$M$ - mean; SD - standard deviation.

\section{Discussion}

The average linear and angular deviations found in this study were within the clinically accepted limit, and are comparable to the previously published results. ${ }^{20-23}$ Accordingly, it can be suggested that the use of the rapid prototype technology to produce virtually planned and designed surgical guides following virtual implant placement is a potentially promising technique that can assist surgeons in placing implants in more precise positions.
Unlike previous studies, which used cast models ${ }^{24,25}$ or cadaver jaws, ${ }^{26,27}$ this study used sheep mandibular bones to simulate in vivo the drilling of a natural bone. In addition, the sheep mandibular bone has an adequate height and a sufficient edentulous area between the anterior and posterior teeth.

For each mandible, the distance between the planned and the actually placed implant axis was measured at 4 points - the linear distance between the central axis at the platform and the apex, the angular deviation and the depth deviation - with the use of the Mimics software. ${ }^{25,27}$

The present study demonstrates the deviation of implant placement performed using a surgical guide (prototype) following 3D virtual planning. The results showed that the mean deviation at the implant platform was $1.82 \pm 0.74 \mathrm{~mm}$, the mean deviation at the implant apex was $1.54 \pm 0.88 \mathrm{~mm}$, the mean depth deviation was $0.44 \pm 0.32 \mathrm{~mm}$, and the mean angular deviation was $3.01 \pm 1.98^{\circ}$.

In a previous in vivo study, the distance between the virtually planned implants and the implants placed using an SLA surgical guide was evaluated. ${ }^{28}$ The results showed a mean deviation between the planned and the positioned implants of $1.45 \pm 1.42 \mathrm{~mm}$ at the implant platform, $2.99 \pm 1.77 \mathrm{~mm}$ at the apex and an angular deviation of $7.25 \pm 2.67^{\circ} .{ }^{28}$ In comparison, our results showed smaller deviations between the planned and the positioned implants, with smaller standard deviations (SDs).

It seems that the implant deviation is influenced by the surgeon's experience. Our findings show slightly higher deviations than those presented by Noharet et al. ${ }^{27}$ This is because in their study, an experienced surgeon placed all dental implants, ${ }^{27}$ while in our study, an inexperienced clinician performed implant placement. This factor has been discussed in other studies, where it was found that the accuracy of implant placement is affected by the surgeon's experience. ${ }^{29,30}$

The implant deviations demonstrated in the present study were slightly higher than those in an in vitro study by Pettersson et al., in which 150 implants were placed in plastic models by using surgical guides designed according to virtual planning. ${ }^{25}$ In their study, the implant deviation at the platform was $0.59 \pm 0.60 \mathrm{~mm}$, with $0.73 \pm 0.73 \mathrm{~mm}$ at the apex, -0.51 to $-0.52 \mathrm{~mm}$ in depth, where the actually placed implants did not reach the depth of the virtually planned implants, and the angular deviation of $0.61 \pm 1.27^{\circ}$. In that study, the surgical guide was designed with 3 anchor pins to stabilize it while drilling. ${ }^{25}$ In contrast, the surgical guide in the current study was designed without any stabilizing pin, which might have had an effect on the stability of the guide during drilling, resulting in more implant deviations. Additionally, the diameters of the sleeves used in our study were bigger by about $0.2 \mathrm{~mm}$ than the drill diameters, which may have contributed to slightly higher deviations. Moreover, sheep mandibular bones are hard and stiff, requiring 
more force during drilling than the plastic models used by Pettersson et al., which the authors said were easy to drill. ${ }^{25}$ Thus, the model material could also have contributed to higher implant deviations in our study.

In a recent systematic review and meta-analysis of 2,238 implants placed using surgical guides, the mean linear coronal deviation was $1.04-1.44 \mathrm{~mm}$ and $1.28-1.58 \mathrm{~mm}$ at the apex, while the average angular deviation was $3.00-3.96^{\circ} .^{31}$ Therefore, the results of the present study did not differ much from the clinical situation.

Conclusions

Within the limitations of this study, it can be concluded that surgical guides produced using the rapid prototype technique (the PolyJet technology) can be applied to minimize the implant placement deviation. However, further clinical trials are suggested.

\section{ORCID iDs}

Enas Abdalla Etajuri (i) https://orcid.org/0000-0002-5389-2298 Eshamsul Suliman (1) https://orcid.org/0000-0002-8438-8107 Wan Adida Azina Mahmood (1) https://orcid.org/0000-0003-0463-3211 Norliza Ibrahim (1) https://orcid.org/0000-0003-0591-1076 Muaiyed Buzayan (1) https://orcid.org/0000-0002-6691-2008 Noorhayati Raja Mohd (1) https://orcid.org/0000-0001-5106-3579

\section{References}

1. Adell R, Lekholm U, Rockler B, Brånemark PI. A 15-year study of osseointegrated implants in the treatment of the edentulous jaw. Int J Oral Surg. 1981;10(6):387-416. doi:10.1016/s0300-9785(81)80077-4

2. Albrektsson T, Zarb G, Worthington P, Eriksson AR. The long-term efficacy of currently used dental implants: A review and proposed criteria of success. Int J Oral Maxillofac Implants. 1986;1 (1):11-25. PMID:3527955

3. Esposito M, Hirsch JM, Lekholm U, Thomsen P. Biological factors contributing to failures of osseointegrated oral implants. (II). Etiopathogenesis. Eur JOral Sci. 1998;106(3):721-764. doi:10.1046/j.0909-8836..t01-6-.x

4. Palmer RM. Risk management in clinical practice. Part 9: Dental implants. Br Dent J. 2010;209(10):499-506. doi:10.1038/sj.bdj.2010.1033

5. Checchi V, Gasparro R, Pistilli R, Canullo L, Felice P. Clinical classification of bone augmentation procedure failures in the atrophic anterior maxillae: Esthetic consequences and treatment options. Biomed Res Int. 2019:2019:4386709. doi:10.1155/2019/4386709

6. Attard NJ, Zarb GA. Long-term treatment outcomes in edentulous patients with implant overdentures: The Toronto study. Int J Prosthodont. 2004;17(4):425-433. PMID:15382778

7. Sun Y, Luebbers HT, Agbaje JO, et al. Accuracy of a dedicated bone-supported surgical template for dental implant placement with direct visual control. J Healthc Eng. 2015;6(4):779-789. doi:10.1260/2040-2295.6.4.779

8. Cushen SE, Turkyilmaz I. Impact of operator experience on the accuracy of implant placement with stereolithographic surgical templates: An in vitro study. J Prosthet Dent. 2013;109(4):248-254. doi:10.1016/s0022-3913(13)60053-0

9. Moin DA, Derksen W, Waars H, Hassan B, Wismeijer D. Computerassisted template-guided custom-designed 3D-printed implant placement with custom-designed 3D-printed surgical tooling: An in vitro proof of a novel concept. Clin Oral Implants Res. 2017;28(5):582-585. doi:10.1111/clr.12838

10. Posadzy M, Desimpel J, Vanhoenacker F. Cone beam CT of the musculoskeletal system: Clinical applications. Insights Imaging. 2018;9(1):35-45. doi:10.1007/s13244-017-0582-1

11. Bornstein MM, Scarfe WC, Vaughn VM, Jacobs R. Cone beam computed tomography in implant dentistry: A systematic review focusing on guidelines, indications, and radiation dose risks. Int J Oral Maxillofac Implants. 2014;29(Suppl):55-77. doi:10.11607/jomi.2014suppl.g1.4

12. Pettersson A, Komiyama A, Hultin M, Näsström K, Klinge B. Accuracy of virtually planned and template guided implant surgery on edentate patients. Clin Implant Dent Relat Res. 2012;14(4):527-537. doi:10.1111/j.1708-8208.2010.00285.x
13. Kulczyk T, Rychlik M, Lorkiewicz-Muszyńska D, Abreu-Głowacka M, Czajka-Jakubowska A, Przystańska A. Computed tomography versus optical scanning: A comparison of different methods of $3 D$ data acquisition for tooth replication. Biomed Res Int. 2019;2019:4985121. doi:10.1155/2019/4985121

14. Arisan V, Karabuda ZC, Pişkin B, Özdemir T. Conventional multislice computed tomography (CT) and cone-beam CT (CBCT) for computer-aided implant placement. Part II: Reliability of mucosasupported stereolithographic guides. Clin Implant Dent Relat Res. 2013;15(6):907-917. doi:10.1111/j.1708-8208.2011.00435.x

15. Bover-Ramos F, Viña-Almunia J, Cervera-Ballester J, PeñarrochaDiago M, García-Mira B. Accuracy of implant placement with computer-guided surgery: A systematic review and meta-analysis comparing cadaver, clinical, and in vitro studies. Int J Oral Maxillofac Implants. 2018;33(1):101-115. doi:10.11607/jomi.5556

16. Bell CK, Sahl EF, Kim YJ, Rice DD. Accuracy of implant placed with surgical guides: Thermoplastic versus 3D printed. Int J Periodontics Restorative Dent. 2018;38(1):113-119. doi:10.11607/prd.3254

17. Turbush SK, Turkyilmaz I. Accuracy of three different types of stereolithographic surgical guide in implant placement: An in vitro study. J Prosthet Dent. 2012;108(3):181-188. doi:10.1016/S0022-3913(12)60145-0

18. Katsoulis J, Pazera P, Mericske-Stern R. Prosthetically driven, computer-guided implant planning for the edentulous maxilla: A model study. Clin Implant Dent Relat Res. 2009;11(3):238-245. doi:10.1111/j.1708-8208.2008.00110.x

19. Wong KV, Hernandez A. A review of additive manufacturing. Int Sch Res Notices. 2012;2012:208760. doi:10.5402/2012/208760

20. Vieira DM, Sotto-Maior BS, Villaça de Souza Barros CA, Reis ES, Francischone CE. Clinical accuracy of flapless computer-guided surgery for implant placement in edentulous arches. Int J Oral Maxillofac Implants. 2013;28(5):1347-1351. doi:10.11607/jomi.3156

21. Cassetta M, Giansanti M, Di Mambro A, Stefanelli LV. Accuracy of positioning of implants inserted using a mucosa-supported stereolithographic surgical guide in the edentulous maxilla and mandible. Int J Oral Maxillofac Implants. 2014;29(5):1071-1078. doi:10.11607/jomi.3329

22. Verhamme LM, Meijer GJ, Bergé SJ, et al. An accuracy study of computer-planned implant placement in the augmented maxilla using mucosa-supported surgical templates. Clin Implant Dent Relat Res. 2015;17(6):1154-1163. doi:10.1111/cid.12230

23. Verhamme LM, Meijer GJ, Soehardi A, Bergé SJ, Xi T, Maal TJJ. An accuracy study of computer-planned implant placement in the augmented maxilla using osteosynthesis screws. Int J Oral Maxillofac Surg. 2017;46(4):511-517. doi:10.1016/j.ijom.2016.10.013

24. Kühl S, Zürcher S, Mahid T, Müller-Gerbl M, Filippi A, Cattin P. Accuracy of full guided vs half-guided implant surgery. Clin Oral Implants Res. 2013;24(7):763-769. doi:10.1111/j.1600-0501.2012.02484.x

25. Pettersson A, Kero T, Söderberg R, Näsström K. Accuracy of virtually planned and CAD/CAM-guided implant surgery on plastic models. JProsthetDent. 2014;112(6):1472-1478. doi:10.1016/j.prosdent.2014.01.029

26. Van Assche N, van Steenberghe D, Guerrero ME, et al. Accuracy of implant placement based on pre-surgical planning of threedimensional cone-beam images: A pilot study. J Clin Periodontol. 2007;34(9):816-821. doi:10.1111/j.1600-051X.2007.01110.x

27. Noharet R, Pettersson A, Bourgeois D. Accuracy of implant placement in the posterior maxilla as related to 2 types of surgical guides: A pilot study in the human cadaver. $J$ Prosthet Dent. 2014;112(3):526-532. doi:10.1016/j.prosdent.2013.12.013

28. Di Giacomo GAP, Cury PR, de Araujo NS, Sendyk WR, Sendyk CL. Clinical application of stereolithographic surgical guides for implant placement: Preliminary results. J Periodontol. 2005;76(4):503-507. doi:10.1902/jop.2005.76.4.503

29. Vasak C, Watzak G, Gahleitner A, Strbac G, Schemper M, Zechner W. Computed tomography-based evaluation of template (NobelGuide ${ }^{\mathrm{TM}}$ )-guided implant positions: A prospective radiological study. Clin Oral Implants Res. 2011;22(10):1157-1163. doi:10.1111/ j.1600-0501.2010.02070.x

30. Park SJ, Leesungbok R, Cui T, Lee SW, Ahn SJ. Reliability of a CAD/ CAM surgical guide for implant placement: An in vitro comparison of surgeons' experience levels and implant sites. Int J Prosthodont. 2017;30(4):367-369. doi:10.11607/ijp.5179

31. Tahmaseb A, Wu V, Wismeijer D, Coucke W, Evans C. The accuracy of static computer-aided implant surgery: A systematic review and meta-analysis. Clin Oral Implants Res. 2018;29(Suppl 16):416-435. doi:10.1111/clr.13346 